\title{
Antimicrobial resistance and virulence characterization of Staphylococcus aureus and coagulase-negative staphylococci from imported beef meat
}

\author{
Kamelia Osman ${ }^{1}$, Avelino Alvarez-Ordóñez ${ }^{2}$, Lorena Ruiz ${ }^{3}$, Jihan Badr ${ }^{4}$, Fatma ElHofy ${ }^{5}$, Khalid S. Al-Maary ${ }^{6}$, \\ Ihab M. I. Moussa ${ }^{6}$, Ashgan M. Hessain ${ }^{7}$, Ahmed Orabi ${ }^{1}$, Alaa Saad ${ }^{4}$ and Mohamed Elhadidy ${ }^{8,9^{*}}$
}

\begin{abstract}
Background: The objectives of this study were to characterize the diversity and magnitude of antimicrobial resistance among Staphylococcus species recovered from imported beef meat sold in the Egyptian market and the potential mechanisms underlying the antimicrobial resistance phenotypes including harboring of resistance genes ( $m e c A$, cfr, gyrA, gyrB, and $g r / A$ ) and biofilm formation.

Results: The resistance gene mecA was detected in 50\% of methicillin-resistant non-Staphylococcus aureus isolates (4/8). Interestingly, our results showed that: (i) resistance genes mecA, gyrA, gyrB, grlA, and cfr were absent in Staphylococcus hominis and Staphylococcus hemolyticus isolates, although S. hominis was phenotypically resistant to methicillin (MR-non-S. aureus) while S. hemolyticus was resistant to vancomycin only; (ii) S. aureus isolates did not carry the mecA gene (100\%) and were phenotypically characterized as methicillin- susceptible S. aureus (MSS); and (iii) the resistance gene mecA was present in one isolate (1/3) of Staphylococcus lugdunensis that was phenotypically characterized as methicillin-susceptible non-S. aureus (MSNSA).

Conclusions: Our findings highlight the potential risk for consumers, in the absence of actionable risk management information systems, of imported foods and advice a strict implementation of international standards by different venues such as CODEX to avoid the increase in prevalence of coagulase positive and coagulase negative Staphylococcus isolates and their antibiotic resistance genes in imported beef meat at the Egyptian market.
\end{abstract}

Keywords: Coagulase-positive staphylococci, Coagulase-negative staphylococci, Antibiotic resistance genes, Imported beef meat

\section{Background}

Contamination of meat with foodborne pathogens represents a major public health threat. The increasing volume of trade and travel is considered as a potential risk factor facilitating the global transport and dissemination of pathogenic bacteria in food. Imported animal products are considered as a clear example, and risk analyses have been previously applied to characterize these

\footnotetext{
*Correspondence: mm_elhadidy@mans.edu.eg

${ }^{8}$ Department of Bacteriology, Mycology and Immunology, Faculty of Veterinary Medicine, Mansoura University, Mansoura 35516, Egypt Full list of author information is available at the end of the article
}

products [1]. This risk analyses strategy have been implemented following the World Trade Organization (WTO) creation. The application of sanitary and phytosanitary measures in response to the sanitary and phytosanitary measures agreement (SPS Agreement) [2] requires the WTO members to remove barriers on the trade of agricultural products, except in situations where such trade can potentially create risk to the animal, human or plant health in the importing country.

Staphylococcus aureus is one of the most common foodborne pathogens causing food poisoning outbreaks worldwide [3]. Other than S. aureus, the clinical and 
veterinary importance of coagulase-positive staphylococci (CPS) and coagulase-negative staphylococci (CNS) have often been neglected. In recent years, the risk of CPS and CNS has been highlighted by recent reports [4-6] with special reference to the CNS that have been commonly found in food [7, 8]. CNS have been recorded as conveying vector for virulence genes and have been implicated in some cases of food poisoning [9]. Furthermore, food-related staphylococci could act as dissemination vectors for antibiotic resistance genes to other potentially pathogenic microorganisms causing immediate threat to the public health. The mecA-harboring CNS (MRCNS) have been reported to have a reservoir in animal farm facilities and in meat products, with the ability to be conveyed to $S$. aureus [10-12].

The remarkable global concern of antibiotic- resistant pathogens in the food chain and the potential for these resistant pathogens to spread through the food chain prompted the Codex Alimentarius Commission to establish an ad hoc Intergovernmental Task Force on antimicrobial resistance. The main task of this commission is to apply a complete risk assessment strategy on the use of antimicrobials belonging to both clinical and veterinary classes. While domestic control over antimicrobial usage policies and monitoring is achievable, negligible information is available for imported food [13], with special reference to beef meat that has been incriminated to contribute to the emergence of multidrug resistance among humans through the dispersion of resistance genes carried by resistant pathogens transmitted by contaminated meat $[14,15]$.

Livestock-associated methicillin-resistant $S$. aureus (LA-MRSA) have acquired a number of novel and unusual antimicrobial resistance genes including multiresistance genes such as the $c f r$ gene, that confers resistance to phenicols, lincosamides, oxazolidinones, pleuromutilins, and streptogramin A [16]. Oxazolidinones are last resort antimicrobial agents for the control of serious infections caused by MRSA and vancomycinresistant enterococci in humans. MRSA is also notoriously difficult to treat due to resistance to $\beta$-lactams (including penicillin, oxacillin, and methicillin) represent a class of antibiotics generally prescribed as the first line of defense against clinical infections caused by staphylococci, which include drugs like penicillin, oxacillin, and methicillin. This resistance was attributed to the carriage of mecA. The mecA gene encodes a different form of penicillin-binding protein, $\mathrm{PBP} 2 \mathrm{a}$, which $\beta$-lactam drugs cannot inactivate.

Therefore, the objectives of this study were to characterize the diversity of Staphylococcus strains recovered from imported meat sold in the Egyptian market and to assess recovered isolates as potential dispersion vectors for the spread of antimicrobial resistance. To achieve that aim, Staphylococcus isolates were tested for the presence of antimicrobial resistance phenotypes and genetic determinants (mecA, cfr, gyrA, gyrB, and $g r l A$ ) and for their biofilm formation.

\section{Methods \\ Imported beef meat samples}

A total of 100 imported frozen meat samples were delivered to the Department of Poultry Diseases, Animal Health Research, Institute, Dokki, Egypt, as a routine microbiological analysis check for foodborne pathogens. Samples were collected by the food hygiene officials in ice-boxes from different supermarket chains as well as butcher shops located in the Great Cairo Zone. The meat samples ( $25 \mathrm{~g}$ ) were suspended in $225 \mathrm{ml}$ sterile phosphate buffered saline (PBS, pH 7.4) and homogenized in a stomacher (Lab-Blender 400, PBI, Milan, Italy) for $10 \mathrm{~min}$. A total of $25 \mathrm{ml}$ of the homogenate were added to $10 \mathrm{ml}$ of Giolitti-Cantoni broth (BD Diagnostics, Franklin Lakes, NJ, USA). The tubes were incubated at $37^{\circ} \mathrm{C}$ for $18-24 \mathrm{~h}$ with shaking at $200 \mathrm{rpm}$. Ten microliter aliquots of the enriched cultures were seeded on Baird Parker agar (BD Diagnostics, Franklin Lakes, NJ, USA), supplemented with egg yolk tellurite emulsion. The plates were incubated at $37^{\circ} \mathrm{C}$ for $18-24 \mathrm{~h}$ and recovered single colonies were streaked onto blood agar plates (TSA with $5 \%$ sheep blood), and further incubated at $37^{\circ} \mathrm{C}$ for $12-18 \mathrm{~h}$. Characteristic staphylococci colonies (black, with or without a halo) were further identified based on Gram stain, catalase assay, tube coagulase test and further biochemical identification tests referred in standard diagnostic tables [17].

\section{Determination of virulence factors Production of hemolysins}

Production of $\alpha-, \beta$ - and $\gamma$-hemolysins was detected by streaking each staphylococcal isolate on blood agar plates containing 5\% sheep red blood cells following the protocol previously developed [18].

\section{Vero cell cytotoxicity assay}

The ability of the isolated staphylococci to initiate degeneration of Vero cells was microscopically evaluated following the validated methodology described elsewhere [19] with minor modifications. The cytotoxicity assay was carried out using Vero (African green monkey kidney) cells in 96-well microtiter trays. Suspensions of each tested strain in distilled water were adjusted to 0.5 McFarland standard. Then, $20 \mu \mathrm{l}$ of bacterial suspensions were added to $3.5 \mathrm{ml}$ of brain heart infusion broth (BBL, Becton-Dickinson Microbiology Systems). The tubes were incubated 2 days at $35^{\circ} \mathrm{C}$, and thereafter for 
2 days at room temperature. After centrifugation of bacterial broth cultures, $20 \mu \mathrm{l}$ of supernatants were added in triplicate to $180 \mu \mathrm{l}$ of cell culture medium. After incubation at $37{ }^{\circ} \mathrm{C}$, in a humid atmosphere and $5 \% \mathrm{CO}_{2}$, the cytotoxic effect of each staphylococcal strain on the Vero monolayer morphology was microscopically perceived up to 5 days.

\section{Phenotypic determination of the antibiotic resistance profile}

The disk diffusion method was used to investigate the antibiotic resistance phenotype of the 23 Staphylococcus spp. recovered from the imported beef meat on Mueller-Hinton agar plates as previously described [20]. Escherichia coli NCIMB 50034 and S. aureus ATCC 25923 were included as controls. The antibiotics tested were selected from two categories, as follows [21]: (i) Critically important antibiotics: ampicillin-sulbactam $(20 \mu \mathrm{g})$, methicillin $(5 \mu \mathrm{g})$, oxacillin $(1 \mu \mathrm{g})$, penicillin $(10 \mu \mathrm{g})$, ciprofloxacin $(5 \mu \mathrm{g})$, erythromycin $(15 \mu \mathrm{g})$, gentamicin $(10 \mu \mathrm{g})$, vancomycin $(30 \mu \mathrm{g})$ and (ii) Highly important antibiotics: chloramphenicol $(30 \mu \mathrm{g})$, clindamycin $(2 \mu \mathrm{g})$, tetracycline $(30 \mu \mathrm{g})$, and sulfamethoxazole/ trimethoprim $(25 \mu \mathrm{g})$.

\section{Molecular characterization}

Overnight cultures of all Staphylococcus isolates were subjected to the boiling method for the preparation of cell lysates to be used for DNA templates. Genus-specific confirmation was carried out through PCR using the $16 \mathrm{~S}$ rRNA gene Staphylococcus-genus-specific primers and cycling conditions previously described [22]. S. aureus ATCC 43300 and E. coli NCIMB 50034 were used as positive and negative controls, respectively. All confirmed staphylococci were submitted to further molecular analyses for the detection of the mecA gene, that is considered as the gold-standard for MRSA confirmation [23]. Four additional antimicrobial resistance markers frequently reported in $S$. aureus were screened by PCR, including the $\operatorname{gyr} A, \operatorname{gyr} B$, and $g r l A$ genes that are responsible for quinolone resistance and the $c f r$ gene (chloramphenicol-florfenicol resistance gene), conferring resistance to several classes of antibiotics (phenicols, lincosamides, oxazolidinones, pleuromutilins, and streptogramin A; known as the PhLOPSA phenotype). PCR amplifications were carried out with a GeneAmp PCR System 2400 (Perkin-Elmer, Weiterstadt, Germany) using the primers and the cycling conditions previously described [8]. Two microliters of template DNA were added to $23 \mu \mathrm{l}$ of master mix containing $1 \mu \mathrm{M}$ of each primer and $3 \mathrm{U}$ of Taq polymerase. The amplicons were screened by gel-electrophoresis on $1.5 \%(\mathrm{w} / \mathrm{v})$ agarose gels in TBE buffer and visualized following ethidium bromide staining. S. aureus reference strains EMRSA-15 and ATCC 25923 were used was used as a positive controls for the mecA and the $c f r$ genes, respectively.

\section{Biofilm formation}

The tube method (TM) and Congo red agar (CRA) method previously described [24] were followed to assess the ability for biofilm and slime formation by the 23 Staphylococcus isolates using the following international reference strains as controls: the non-biofilm producers Staphylococcus epidermidis ATCC 12228 and Staphylococcus warneri ATCC 10209 (negative controls), and the biofilm producers S. epidermidis ATCC 35983, Staphylococcus simulans ATCC 27851 and Staphylococcus xylosus ATCC 29979 (positive controls). For the TM, adherence was observed as a ring formation on the inside walls of the test tube when stained with crystal violet. Regarding the interpretation of the TM results, strains were classified as strongly adherent $(+)$ or negative $(-)$. Results of the CRA method were interpreted as follows: very black, black and almost black colonies were considered to be strong biofilm formers, while very red, red and bordeaux colonies were classified as negative strains for biofilm formation.

\section{Correlation analyses}

Pearson's correlation was used to analyze the association between all studied phenotypic and genotypic features. Univariate analyses (Chi square test, $p<0.05$ ) were performed to identify variables significantly associated. The $p$ values $<0.05$ were considered statistically significant. Statistical analysis and data representation were done using R software (3.3.2).

\section{Results}

Isolation and characterization of Staphylococcus spp. from imported beef meat samples

In this study, a total of 23 staphylococcal isolates were recovered from 100 imported meat samples (23\%), including CPS strains (12/23) and CNS strains (11/23) (Table 2). The 23 Staphylococcus spp. (S. aureus, $\mathrm{n}=3$; $S$. hyicus, $\mathrm{n}=6$; S. intermedius, $\mathrm{n}=3$; S. epidermidis, $\mathrm{n}=1$; S. hemolyticus, $\mathrm{n}=1 ; S$. hominis, $\mathrm{n}=1$; S. lugdunensis, $\mathrm{n}=3$; S. simulans, $\mathrm{n}=1$; and $S$. scuri, $\mathrm{n}=4$ ) isolates were cytotoxic to Vero cells. The three types of hemolysis were manifested as $\alpha$-, $\beta$ - and $\gamma$-hemolysins at a percentage of $17.4,47.8$, and $34.8 \%$, respectively (Table 1 ).

\section{Biofilm formation phenotype}

Using the tube method (TM), a total of 18 isolates (78.3\%) were classified as positive for biofilm formation ability, while 5 isolates $(21.7 \%)$ were considered negative. Using CRA method, 7 of the 23 Staphylococcus spp. 


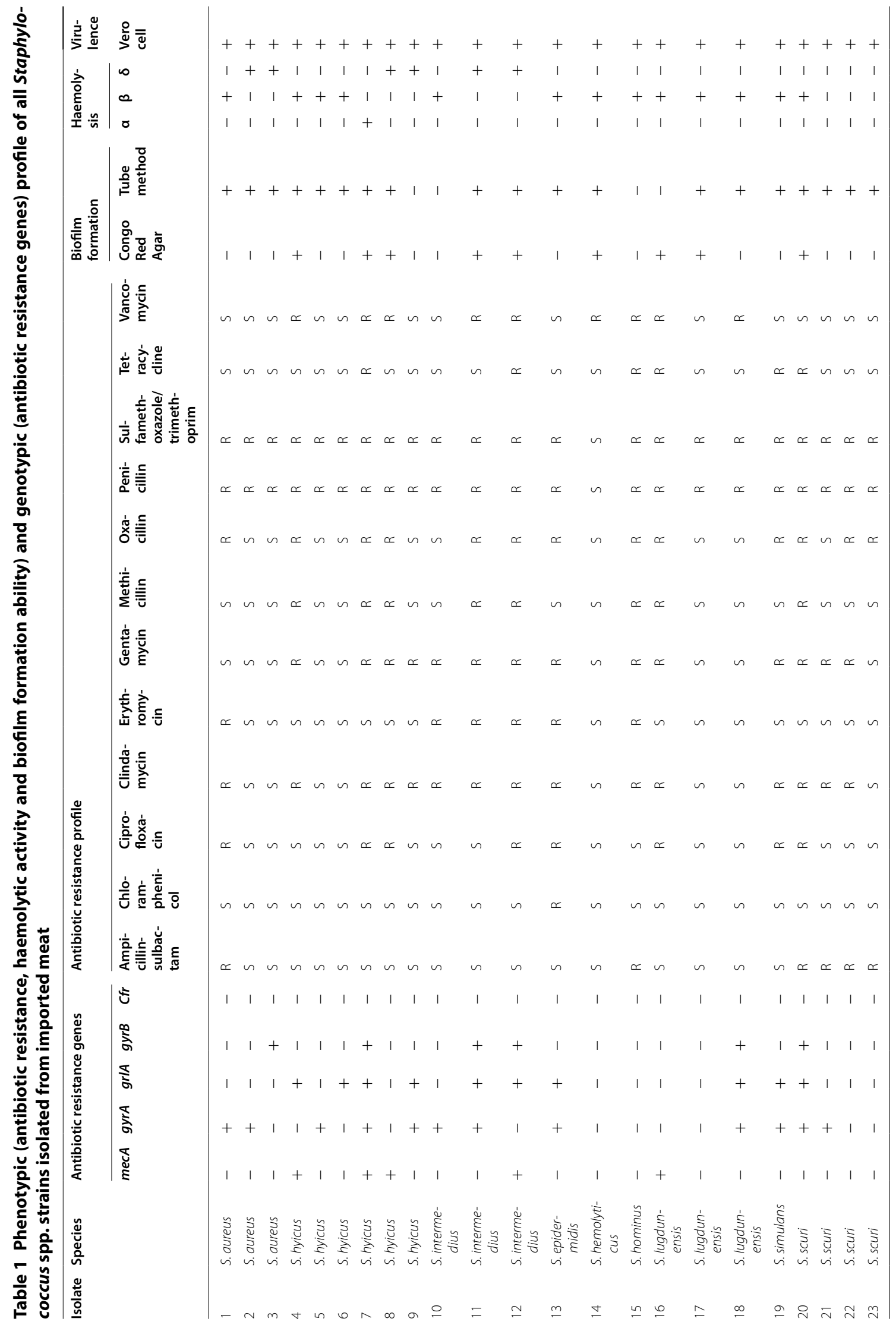


isolates (30.4\%) showed black colonies with shriveled lucent texture whereas 16 (69.6\%) isolates showed pink colored colonies with mucoid appearance on the CRA plates that were interpreted as negative for biofilm formation (Table 1).

\section{Antibiotic resistance phenotypic profile}

The diversity in occurrence of antibiotic resistance among the tested Staphylococcus spp. isolates is outlined in Tables 1 and 2 . The 23 isolates were resistant to at least one antibiotic. Less than $50 \%$ of the isolates exhibited resistance to the $\beta$-lactams ampicillin $(6 / 23)$ and methicillin $(8 / 23)$, erythromycin $(6 / 23)$, chloramphenicol $(1 / 23)$, ciprofloxacin $(7 / 23)$, vancomycin $(9 / 23)$, and tetracycline $(6 / 23)$ (Table 2). Ninety six percent of the isolates $(22 / 23)$ were resistant to penicillin and sulfamethoxazole/trimethoprim, while only one isolate was resistant to chloramphenicol (Table 1). MDR, defined as resistance to $\geq 3$ antimicrobial classes, was observed in 16 Staphylococcus isolates. Fifteen multidrug resistance (MDR) combination patterns were observed (Table 2). The penicillin/ sulfamethoxazole/trimethoprim (P/SXT) resistance phenotype was evident in $14 / 15$ of these combinations.

\section{Antimicrobial resistance genes}

From the 23 screened isolates, five isolates ( $3 / 6$ S. hyicus; $1 / 3$ S. intermedius; $1 / 3 \mathrm{~S}$. lugdunensis) were identified as positive for mecA $(5 / 23)$. Four of the 13 oxacillinresistant isolates harbored the $m e c A$ gene, while 4 of the

Table 2 Antimicrobial resistance patterns among Staphylococcus spp. strains isolated from imported beef meat

\begin{tabular}{lllr}
\hline Antibiotics & $\begin{array}{l}\text { Number } \\
\text { of antibiotics }\end{array}$ & $\begin{array}{l}\text { Total number } \\
\text { of isolates }\end{array}$ & $\%$ \\
\hline VA & 1 & $1 / 23$ & 4 \\
P, SXT & 2 & $6 / 23$ & 26 \\
P, TE, VA, SXT & 4 & $1 / 23$ & 4 \\
P, CN, E, DA, SXT & 5 & $2 / 23$ & 9 \\
P, OX, CN, DA, SXT & & & \\
P, OX, SAM, CN, DA, SXT & 6 & $3 / 23$ & 13 \\
P, OX, MET, CN, DA, SXT & & & \\
P, OX, E, DA, C, SXT, CIP & 7 & $5 / 23$ \\
P, CN, DA, TE, VA, SXT, CIP & & & \\
P, OX, CN, DA, TE, SXT, CIP & & & \\
P, OX, MET, CN, DA, VA, SXT & & & \\
P, OX, MET, CN, DA, VA, SXT, CIP & 8 & $2 / 23$ \\
P, OX, MET, CN, E, DA, TE, VA, SXT & 9 & $3 / 23$ \\
P, OX, MET, CN, E, DA, VA, SXT, CIP & & & \\
P, OX, MET, SAM, E, DA, TE, VA, SXT & & & \\
\hline
\end{tabular}

C chloramphenicol, CIP ciprofloxacin, $C N$ gentamycin, $D A$ clindamycin, $E$ erythromycin, MET methicillin, $O X$ oxacillin, $P$ penicilin, SAM ampicillinsulbactam, SXT sulfamethoxazole/trimethoprim, TE tetracycline, $V A$ vancomycin
8 methicillin resistant isolates carried the mecA gene (Table 3).

Interestingly, the following three observations were recorded: (i) although $S$. hominis and S. hemolyticus isolates were resistant to methicillin and vancomycin, respectively, the resistance genes $m e c A, \operatorname{gyr} A, \operatorname{gyr} B, \operatorname{grl} A$ and $c f r$ were absent. (ii) three $S$. aureus isolates did not carry the $m e c A$ gene (100\%) and were phenotypically characterized as MSS; and (iii) one S. lugdunensis isolate was observed to harbor the mecA resistance gene but was phenotypically characterized as methicillin-susceptible non-S. aureus (MSNSA). The resistance gene $m e c A$ was detected in $4 / 8$ (50\%) methicillin-resistant non-S. aureus (MRNSA) isolates (Table 3). Of the three MSSA isolates, two carried the gyrA gene $(66.66 \%)$ and one carried the gyrB gene (33.33\%) (Table 1). The cfr gene was absent in all Staphylococcus isolates. The non-cfr-conveying CNS showed extensive resistance to several antimicrobials irrespective of those incorporated in the $c f r$-transmitted PhLOPSA phenotype (conferring resistance to several classes of antibiotics (phenicols, lincosamides, oxazolidinones, pleuromutilins, and streptogramin A; PhLOPSA phenotype) (Table 1). Phenotypically, 40\% (8/20) of NSA (non Staphylococcus aureus) isolates were methicillin resistant, while the mecA gene was detected in only $25 \%(5 / 20)$ of isolates.

\section{Correlation analyses}

Correlation analyses showed that presence of $m e c A$ was directly correlated with resistance to ciprofloxacin, gentamicin, methicillin, oxacillin, and vancomycin (Pearson's correlation coefficients of $0.50,0.42,0.72,0.46$ and 0.66 , respectively) (Fig. 1). There were several instances of cooccurrence of resistance to various antibiotics. Indeed, resistance to various antibiotics was directly correlated. For instance, resistance to methicillin was significantly associated with resistance to ciprofloxacin (Pearson's correlation coefficient of 0.43), clindamycin (Pearson's correlation coefficient of 0.53), gentamicin (Pearson's correlation coefficient of 0.59), oxacillin (Pearson's correlation coefficient of 0.64 ), tetracycline (Pearson's correlation coefficient of 0.61 ) and vancomycin (Pearson's correlation coefficient of 0.72). Similarly, a high correlation between resistances to several other antibiotics was found (Fig. 1). In addition, biofilm formation, as assessed by the CRA tests, was directly correlated with $m e c A$ presence (Pearson's correlation coefficient of 0.66 ), methicillin resistance (Pearson's correlation coefficient of 0.72) and vancomycin resistance (Pearson's correlation coefficient of 0.63).

\section{Discussion}

Globally, an increasing recognizable concern exists on the status of antimicrobial resistant microbial contaminants in the food chain and their capacity to be widely 
Table 3 Prevalence of the mecA gene in imported beef samples

\begin{tabular}{|c|c|c|c|c|c|c|}
\hline \multirow[t]{2}{*}{$\begin{array}{l}\text { Staphylococcus spp. } \\
\text { ( } \mathrm{n}=\text { number of isolates) }\end{array}$} & \multirow[t]{2}{*}{$n=$ of MRS } & \multicolumn{2}{|c|}{$\begin{array}{l}\text { Presence } \\
\text { of } \operatorname{mec} A g e n e\end{array}$} & \multirow[t]{2}{*}{$n=$ of MSS } & \multicolumn{2}{|c|}{$\begin{array}{l}\text { Precence of } m e c A \\
\text { gene }\end{array}$} \\
\hline & & $\mathrm{n}=$ & $\%$ & & $\mathrm{n}=$ & $\%$ \\
\hline S. aureus $(n=3)$ & 0 & 0 & 0 & 3 & 0 & 0 \\
\hline S. hyicus $(n=6)$ & 3 & 3 & 100 & 3 & 0 & 0 \\
\hline S. intermedius $(n=3)$ & 2 & 1 & 50 & 1 & 0 & 0 \\
\hline S. epidermidis $(n=1)$ & 0 & 0 & 0 & 1 & 0 & 0 \\
\hline S. hemolyticus $(n=1)$ & 0 & 0 & 0 & 1 & 0 & 0 \\
\hline S. hominus $(n=1)$ & 1 & 0 & 0 & 0 & 0 & 0 \\
\hline S. lugdunensis $(n=3)$ & 1 & 0 & 0 & 2 & 1 & 50 \\
\hline S. simulans $(n=1)$ & 0 & 0 & 0 & 1 & 0 & 0 \\
\hline S. scuri $(n=4)$ & 1 & 0 & 0 & 3 & 0 & 0 \\
\hline Total & 8 & 4 & 50 & 15 & 1 & 6.7 \\
\hline
\end{tabular}

MRS methicillin resistant Staphylococcus, MSS methicillin susceptible Staphylococcus

dispersed through the international trade of food. This prompted the Codex Alimentarius Commission to establish an ad hoc Intergovernmental Task Force on Antimicrobial Resistance in 2007, bearing in mind the occurrence of national and regional diversity in antimicrobial misuse, human subjection to resistant microorganisms and determinants and their prevalence in foodborne pathogens. Egypt imports different meat types to fill the gaps in animal protein supply. According to the U.S. Meat Export Federation (USMEF) that examines key statistics and trends in beef and pork trade from 2008 to 2017, Egypt's projection for beef-importing in 2017 would reach about 332,000 metric tons of meat imports and this is supposed to grow to 2025 by $52.28 \%$ [25]. While the importation of beef meat in Egypt is crucial to close the gap in animal protein requirements, monitoring the frequency of antimicrobial resistance in imported meat must assure that quality and safety standards are met.

The spread of MRSA is a serious public health concern for both human and veterinary medicine. Due to the occurrence of MRSA, methicillin and other $\beta$-lactamic antibiotics have become useless for clinical therapy, leaving the term MRSA to be used to describe $S$. aureus strains resistant to effectively all $\beta$-lactamase-resistant penicillins and harboring the $m e c A$ gene [23]. Although the development and spread of multiple antibioticresistant MRSA have gained much attention over the past years, yet the role of imported meat has not been given much attention. In a Danish study, Agersø et al. reported that MRSA was found in $18 \%$ of the imported broiler meat and $7.5 \%$ of the imported pork [26]. MRSA are often resistant to other antimicrobials different to methicillin, highlighting the necessity for new and effective antimicrobials. Attributed to their extended antimicrobial spectra, fluoroquinolone compounds such as ciprofloxacin and norfloxacin were recommended as useful candidates for eradicating MRSA [27]. Nonetheless, due to the misuse of these compounds in the clinical practice, resistance of MRSA to these compounds has been observed [28]. For this reason ciprofloxacin is not recommended to be used in empirical therapy against MRSA infections. Furthermore, the use of other fluoroquinolones is only allowed following accurate antimicrobial susceptibility testing. Nonetheless, vancomycin remains the drug of choice to treat MRSA infections [29].

Identification of methicillin resistant staphylococci in the laboratory is often problematic due to difficulty in detecting heterogeneous methicillin-oxacillin resistance in staphylococci [30,31]. Moreover, Standard interpretive breakpoints for oxacillin susceptibility reporting published by the CLSI (formerly the National Committee for Clinical and Laboratory Standards) were changed in 2004, and NSA isolates of veterinary origin are now more likely than in previous years to be deemed resistant by testing laboratories that use those guidelines [32].

In this study, the susceptibility of 23 Staphylococcus spp. strains isolated from imported meat to 12 antibiotics from different classes was evaluated. An extreme resistance was found against penicillin and sulfamethoxazole/ trimethoprim as compared to other tested antibiotics, which could be attributed to the extensive use of these antibiotics in treating mastitis cases and/or as growth promoters in animal feed in the countries from which the beef meat was imported. Resistance to other clinically important antibiotics, including $\beta$-lactamic antibiotics (such as ampicillin-sulbactam, methicillin, oxacillin), fluoroquinolones (ciprofloxacin), macrolides (erythromycin), aminoglycosides (gentamicin), glycopeptides 


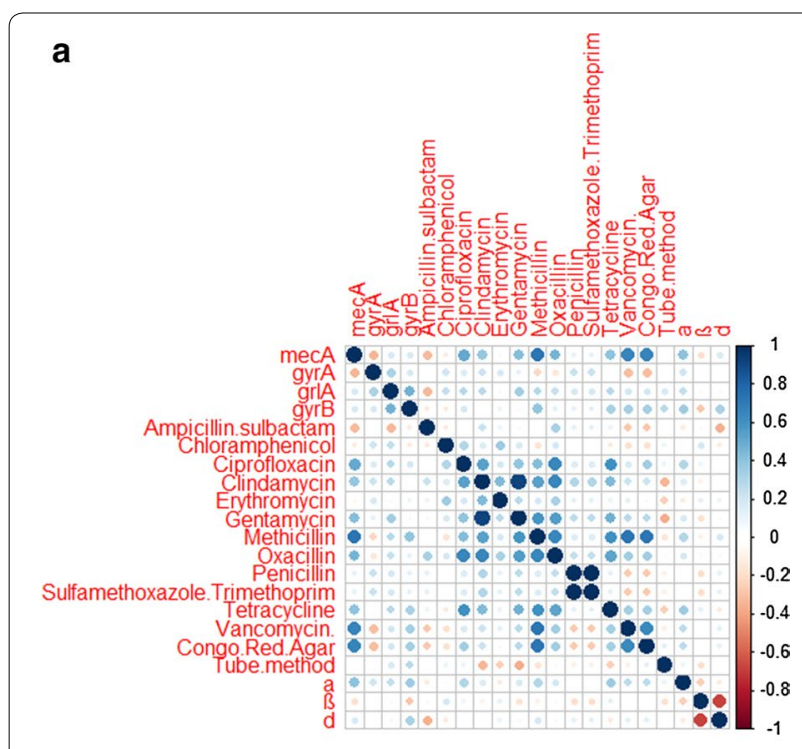

b

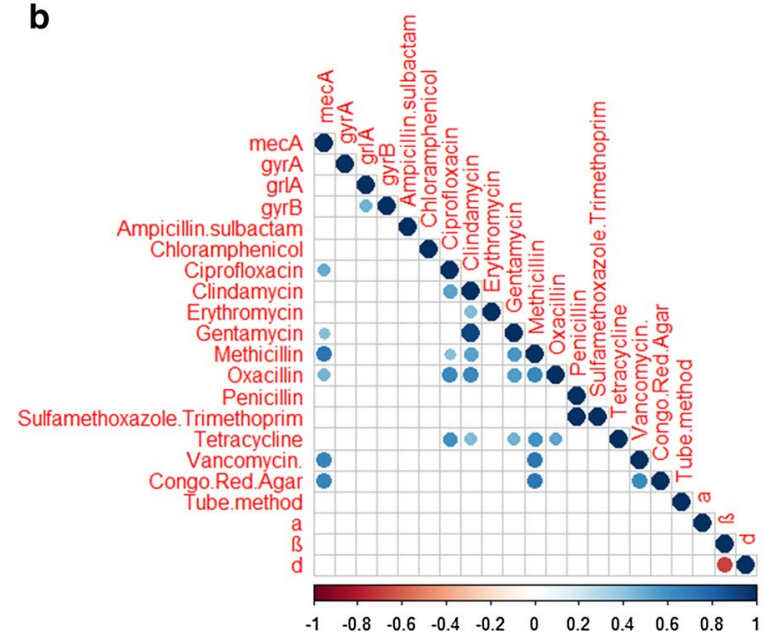

Fig. 1 a Correlation matrix of phenotypic (antibiotic resistance,

haemolytic activity and biofilm formation ability) and genotypic (antibiotic resistance genes) features. b Correlation matrix showing only significant $(p<0.05)$ associations, as assessed by the Chi square test

(vancomycin), lincosamides (clindamycin) and tetracycline also occurred and, in some cases, multidrug resistance phenotypes were identified. Indeed, correlation analyses showed co-occurrence of resistance to series of antibiotics. Extended-spectrum beta-lactamases (ESBL) -producing pathogens are often resistant to fluoroquinolones and aminoglycosides since resistance mechanisms for these classes of antibiotics are often carried on the same large plasmids that contain the genetic elements for ESBL production [33]. Our results corroborate this observation. Thus, for instance, resistance to methicillin was significantly associated with resistance to ciprofloxacin and gentamycin, among others (clindamycin, oxacillin, tetracycline and vancomycin). The colonization ability in conjunction with the occurrence of MDR highlights the hazardous nature of the Staphylococcus spp. isolated from imported beef meat.

The antimicrobial resistance determinants $m e c A$, gyrA, gyrB, grlA and $c f r$, frequently reported in $S$. aureus strains were also screened in recovered isolates. The emergence of the multiple drug resistance gene $c f r$ in staphylococci is of global clinical and veterinary importance that has been previously investigated in staphylococci [34] and has been identified as a phenicol and lincosamide resistance gene [35]. In this study, the absence of the $c f r$ gene among imported beef meat isolates suggests a decreased potential risk as an outcome of harboring the gene in the food chain through imported meat. Furthermore, the absence of the gene $c f r$ poses a significant and interdisciplinary public health positive factor to the Egyptian consumers. One isolate showed chloramphenicol resistance but was negative for the $c f r$ gene. This observation might be attributed to a possible heterogeneous expression of the $c f r$ gene [36] or to different potential chloramphenicol resistance mechanisms.

The mecA gene confers methicillin resistance. It encodes the penicillin binding protein $2 \mathrm{a}$, an enzyme that has low affinity for beta-lactams, and has been reported to lead to resistance to ciprofloxacin, gentamycin, methicillin, oxacillin and vancomycin [37]. In our study, the $m e c A$ gene was carried by 5 out of 23 Staphylococcus spp. isolates, and, as expected, presence of $m e c A$ was directly correlated with resistance to ciprofloxacin, gentamycin, methicillin, oxacillin, and vancomycin. Nevertheless, not all methicillin or oxacillin resistant isolates were mecA positive. It was previously indicated that some isolates missing the mecA gene could be identified as phenotypically resistant to oxacillin (MRSA) [38]. These results suggests that other potential resistance mechanisms might exist. Molecular investigations of a $S$. aureus isolate, which was found to be phenotypically resistant to methicillin but negative for the $m e c A$ gene, were able to identify the presence of a novel mecA homologue, which was found to be associated with cattle [39], suggesting the existence of a zoonotic MRSA reservoir [40]. In 2012, the International Working Group on the Classification of Staphylococcal Cassette Chromosome elements (IWCC) renamed the $m e c A$ variant, $\operatorname{mecC}$ [41]. Methicillinresistant $S$. aureus strains carrying the $m e c C$ gene have been shown to cause a range of infections in humans and appear to be predominantly community associated [40]. The prevalence of $m e c C$ in CNS has been recently reported for 13 European countries, where it has been isolated from 14 different host species (Holmes et al. 42), and an allotype of the mecC gene has been detected in a S. xylosus strain [42]. It is also worth mentioning the fact 
that one S. lugdunensis isolate was observed to harbor the $m e c A$ resistance gene but was phenotypically characterized as MSNSA. The phenotypic susceptibility to oxacillin, methicillin, penicillin and ampicillin ( $\beta$-lactam antibiotic of the penicillin class) regardless of the mecA presence may be attributed to the heterogeneous expression of mecA [43], which is more common in CNS than that in S. aureus [44]. Nevertheless, it should be noted that in 2014, Bhargava and Zhang emphasized the importance of MRCNSs as important reservoirs of mecA that could act as precursors of MRSA [11]. In addition, temperature abuse during storage and transportation to the importing country may result in multiplication of MRS [45]. An additional important finding was introduced by the identification and characterization of another gene on the SCC element called mecR2 that regulates and increases mecA expression when MRSA bacteria encounter $\beta$-lactam drugs [46].

Besides resistance genes, mutation-mediated resistance is especially common among resistances to synthetic antibacterial agents, such as fluoroquinolones and oxazolidinones in S. aureus and other bacterial species [47]. The primers used in this study amplified only the copies of $g y r A, g y r B$, and $g r l A$ that contained mutations in the quinolone resistance-determining regions (QRDRs). In this study, the amplification of a grlA and gyrA product represented the presence of a mutation conferring resistance. Mutations in the gyrB gene does not play an important role in quinolone resistance [48]. Although the presence of resistance genes are a primary reason for antibiotic resistance, the resistance phenotype and gene presence are not exclusively linked in this study. Similarly, this inconsistency was common in other classes of antibiotics, demonstrating that the presence of a certain resistance gene was not necessary an indicator of antibiotic resistance [49]. A potential explanation for this inconsistency could be the lack of expression of some of the resistance genes and the presence of other genes encoding resistance. In addition, chromosomally encoded multidrug resistance pumps have been shown to have other primary functional or structural roles [50].

The connection between microbial biofilms and antibiotic resistance is of considerable interest to biomedical researchers. Previous reports have suggested that a correlation between antibiotic resistance and biofilm formation ability exists, a phenomenon that may be responsible for a decrease in the efficaciousness of antimicrobial agents against $S$. aureus infections [51]. As a consequence of biofilm development, the capability of horizontal gene transfer is increased and may facilitate the dispersion of antibiotic resistance [52]. In the present study, MRS and MDR isolates showed a good potential to form biofilms. In fact, correlation analyses showed that biofilm formation, as assessed by the CRA tests, was directly correlated with mecA presence, methicillin resistance and vancomycin resistance, and biofilm producing MRNSA showed high resistance to almost all antibiotic classes compared to non-producers, which corroborates previous observations [53].

\section{Conclusions}

Despite the alert generated by the outbreaks of foot and mouth disease and swine fever, which have been attributed to international trade of meat, little information or actionable risk management information is available yet on the dissemination of microbial hazards through retail imported meat. This study reveals that imported meat can act as a transmission vector for MRSA or MRNSA harboring the $m e c A$ gene, which may represent a risk for both human and veterinary medicine. The data obtained on the resistance of Staphylococcus spp. to antimicrobials, may be used for implementing an antimicrobial resistance spread monitoring and prevention program.

\section{Abbreviations}

ESBL: extended-spectrum beta-lactamases; CNS: coagulase-negative staphylococci; CPS: coagulase-positive staphylococci (CPS); LA-MRSA: livestockassociated methicillin-resistant Staphylococcus aureus; MDR: multiple drug resistance; MRNSA: methicillin-resistant non-Staphylococcus aureus; MRSA: methicillin-resistant Staphylococcus aureus; MSNSA: methicillin-susceptible non-Staphylococcus aureus; NSA: non Staphylococcus aureus; QRDRs: quinolone resistance-determining regions.

\section{Authors' contributions}

$\mathrm{KO}$ conceived, designed the experiments, analyzed the data and wrote the paper; $A A O, L R$ and $M E$ conducted the data analysis and contributed to the writing of the manuscript. FE, KAM, IM and AH contributed with their scientific advice during the work and revision of the manuscript; $\mathrm{AO}$ and AS contributed with reagents/materials/analysis tools and performed the experiments. All authors read and approved the final manuscript.

\section{Author details}

${ }^{1}$ Department of Microbiology, Faculty of Veterinary Medicine, Cairo University, Giza, Egypt. ${ }^{2}$ Department of Food Hygiene and Technology and Institute of Food Science and Technology, University of León, León, Spain. ${ }^{3}$ Department of Nutrition, Bromatology and Food Technology, Universidad Complutense de Madrid, Madrid, Spain. ${ }^{4}$ Department of Poultry Diseases, Animal Health Research, Institute, Giza, Egypt. ${ }^{5}$ Department of Bacteriology, Immunology and Mycology, Faculty of Veterinary Medicine, Benha University, Moushtohor, Egypt. ${ }^{6}$ Department of Botany and Microbiology, College of Science, King Saud University, Riyadh, Kingdom of Saudi Arabia. ${ }^{7}$ Department of Health Science, College of Applied Studies and Community Service, King Saud University, Riyadh, Kingdom of Saudi Arabia. ${ }^{8}$ Department of Bacteriology, Mycology and Immunology, Faculty of Veterinary Medicine, Mansoura University, Mansoura 35516, Egypt. ${ }^{9}$ Foodborne Pathogens, Scientific Institute of Public Health, Juliette Wytsmanstraat 14, 1050 Brussels, Belgium.

\section{Acknowledgements}

The authors extend their appreciation to the Deanship of Scientific Research at King Saud University for funding the work through the research group Project No.: RGP-162.

Competing interests

The authors declare that they have no competing interests. 


\section{Publisher's Note}

Springer Nature remains neutral with regard to jurisdictional claims in published maps and institutional affiliations.

Received: 23 March 2017 Accepted: 2 May 2017

Published online: 10 May 2017

\section{References}

1. MacDiarmid SC. Risk analysis and the importation of animals and animal products. Rev Sci Tech. 1993;12:1093-107.

2. WTO 2016. World Trade Organization. Sanitary and phytosanitary measures: text of the agreement. The WTO Agreement on the Application of Sanitary and Phytosanitary Measures (SPS Agreement). Centre William Rappard, 154 rue de Lausanne, Geneva, Switzerland.

3. Hennekinne JA, De Buyser ML, Dragacci S. Staphylococcus aureus and its food poisoning toxins: characterization and outbreak investigation. FEMS Microbiol Rev. 2012;36:815-36.

4. Bhumbra S, Mahboubi M, Blackwood RA. Staphylococcus /ugdunensis: novel organism causing cochlear implant infection. Infect Dis Rep. 2014;6:5406.

5. Giormezis N, Kolonitsiou F, Foka A, Drougka E, Liakopoulos A, Makri A, Papanastasiou AD, Vogiatzi A, Dimitriou G, Marangos M, Christofidou M, Anastassiou ED, Petinaki E, Spiliopoulou I. Coagulase-negative staphylococcal bloodstream and prosthetic-device-associated infections: the role of biofilm formation and distribution of adhesin and toxin genes. J Med Microbiol. 2014;63:1500-8.

6. Pinheiro L, Brito Cl, de Oliveira A, Martins PY, Pereira VC, da Cunha Mde L. Staphylococcus epidermidis and Staphylococcus haemolyticus: molecular detection of cytotoxin and enterotoxin genes. Toxins. 2015;7:3688-99.

7. Osman KM, Abd EL-Razik KA, Marie HSH, Arafa A. Coagulase-negative staphylococci collected from bovine milk: species and antimicrobial gene diversity. J Food Saf. 2016;36:89-99.

8. Osman KM, Amer AM, Badr JM, Helmy NM, Elhelw RA, Orabi A, Bakry M, Saad AS. Antimicrobial resistance, biofilm formation and mecA characterization of methicillin-susceptible S. aureus and non-S. aureus of beef meat origin in Egypt. Front Microbiol. 2016;7:222

9. Veras JF, Carmo LS, Tong LC, Shupp JW, Cummings C, Dos Santos DA, Cerqueira MM, Cantini A, Nicoli JR, Jett M. A study of the enterotoxigenicity of coagulase-negative and coagulase-positive staphylococcal isolates from food poisoning outbreaks in Minas Gerais, Brazil. Int J Infect Dis. 2008;12:410-5.

10. Chajęcka-Wierzchowska W, Zadernowska A, Nalepa B, Sierpińska M, Łaniewska-Trokenheim $Ł$. Coagulase-negative staphylococci (CoNS) isolated from ready-to-eat food of animal origin-phenotypic and genotypic antibiotic resistance. Food Microbiol. 2015;46:222-6.

11. Bhargava $K$, Zhang Y. Characterization of methicillin-resistant coagulase-negative staphylococci (MRCoNS) in retail meat. Food Microbiol. 2014;42:56-60.

12. Tulinski P, Fluit AC, Wagenaar JA, Mevius D, van de Vijver L, Duim B. Methicillin-resistant coagulase-negative staphylococci on pig farms as a reservoir of heterogeneous staphylococcal cassette chromosome mec elements. Appl Environ Microbiol. 2012;78:299-304.

13. Doyle MP, Loneragan GH, Scott HM, Singer RS. Antimicrobial resistance: challenges and perspectives. Comp Rev Food Sci Food Saf. 2013;12:234-48.

14. Alabi SA, Frielinghaus $L$, Grobusch MP, Köck R, Becker K, Issifou S, Kremsner PG, Peters G, Mellmann A. The risk to import ESBL-producing Enterobacteriaceae and Staphylococcus aureus through chicken meat trade in Gabon. BMC Microbiol. 2014;14:286.

15. Card R, Vaughan K, Bagnall M, Spiropoulos J, Cooley W, Strickland T, Davies R, Anjum MF. Virulence characterization of Salmonella enterica isolates of differing antimicrobial resistance recovered from UK livestock and imported meat samples. Front Microbiol. 2016;7:640.

16. Long KS, Poehlsgaard J, Kehrenberg C, Schwarz S, Vester B. The Cfr rRNA methyltransferase confers resistance to phenicols, lincosamides, oxazolidinones, pleuromutilins, and streptogramin A antibiotics. Antimicrob Agents Chemother. 2006;50:2500-5.
17. Bannerman T. Staphylococcus, Micrococcus, and other catalase positive cocci that grow aerobically. In: Murray PR, Baron EJ, Jorgensen JH, et al., editors. Manual of clinical microbiology. Washington, DC: ASM Press; 2003. p. 384-404.

18. Futagawa-Saito K, Ba-Thein W, Sakurai N, Fukuyasu T. Prevalence of virulence factors in Staphylococcus intermedius isolates from dogs and pigeons. BMC Vet Res. 2006;2:4.

19. Tao M, Yamashita H, Watanabe K, Nagatake T. Possible virulence factors of Staphylococcus aureus in a mouse septic model. FEMS Immunol Med Microbiol. 1999;23:135-46.

20. CLSI. Performance standards for antimicrobial susceptibility testing. Clinical and Laboratory Standards Institute 2007, CLSI M100-S17, Wayne, PA, USA.

21. WHO World Health Organization. Critically important antimicrobials for human medicine-3rd rev. WHO Press, World Health Organization, 20 Avenue Appia, 1211 Geneva 27, Switzerland; 2012.

22. Zhang K, Sparling J, Chow BL, Elsayed S, Hussain Z, Church DL, Gregson DB, Louie T, Conly JM. New quadriplex PCR assay for detection of methicillin and mupirocin resistance and simultaneous discrimination of Staphylococcus aureus from coagulase-negative staphylococci. J Clin Microbiol. 2004:42:4947-55.

23. Paterson GK, Harrison EM, Holmes MA. The emergence of mecC methicillin-resistant Staphylococcus aureus. Trends Microbiol. 2014;22:42-7.

24. Mathur T, Singhal S, Khan S, Upadhyay DJ, Fatma T, Rattan A. Detection of biofilm formation among the clinical isolates of staphylococci: an evaluation of three different screening methods. Indian J Med Microbiol. 2006;24:25-9.

25. USDA 2016 United States Department of Agriculture Foreign Agricultural Service Foreign Ag ServiceVerified account @USDAForeignAg.

26. Agers $\varnothing$ Y, Hasman H, Cavaco LM, Pedersen K, Aarestrup FM. Study of methicillin resistant Staphylococcus aureus (MRSA) in Danish pigs at slaughter and in imported retail meat reveals a novel MRSA type in slaughter pigs. Vet Microbiol. 2012;157:246-50.

27. Gilbert MJ, Boscia A, Kobasa WD, Kaye D. Enoxacin compared with vancomycin for the treatment of experimental methicillin-resistant Staphylococcus aureus endocarditis. Antimicrob Agents Chemother. 1986;29:461-3.

28. Pai V, Rao VI, Rao SP. Prevalence and antimicrobial susceptibility pattern of methicillin-resistant Staphylococcus aureus [MRSA] isolates at a tertiary care hospital in Mangalore, South India. J Lab Phys. 2010;2:82-4.

29. Gade ND, Qazi MS. Fluoroquinolone therapy in Staphylococcus aureus infections: where do we stand? J Lab Phys. 2013;5:109-12.

30. Tenover FC, Goering RV. Methicillin-resistant Staphylococcus aureus strain USA300: origin and epidemiology. J Antimicrob Chemother. 2009;64:441-6.

31. Brown DFJ. Detection of methicillin/oxacillin resistance in staphylococci. J Antimicrob Chemother. 2002;48(S1):65-70.

32. NCCLS National Committee for Clinical Laboratory Standards. Performance standards for antimicrobial disk and dilution susceptibility tests for bacteria isolated from animals; informational supplement. 2004, Document M31-S1. Wayne, Pa: NCCLS; 2004.

33. Karam G, Chastre J, Wilcox MH, Vincent J. Antibiotic strategies in the era of multidrug resistance. Crit Care. 2016;20:136

34. Wang Y, He T, Schwarz S, Zhao Q, Shen Z, Wu C, Shen J. Multidrug resistance gene $\mathrm{cfr}$ in methicillin-resistant coagulase-negative staphylococci from chickens, ducks, and pigs in China. Int J Med Microbiol. 2013:303:84-7.

35. Witte W, Cuny C. Emergence and spread of cfr-mediated multiresistance in staphylococci: an interdisciplinary challenge. Future Microbiol. 2011;6:925-31

36. Terlizzi V, Carnovale V, Castaldo G, Castellani C, Cirilli N, Colombo C, Corti F, Cresta F, D'Adda A, Lucarelli M, Lucidi V, Macchiaroli A, Madarena E, Padoan R, Quattrucci S, Salvatore D, Zarrilli F, Raia V. Clinical expression of patients with the D1152H CFTR mutation. J Cyst Fibros. 2015;14:447-52.

37. Lee JH. Methicillin (oxacillin)-resistant Staphylococcus aureus strains isolated from major food animals and their potential transmission to humans. Appl Environ Microbiol. 2003;69:6489-94. 
38. Lee JH, Jeong JM, Park YH, Choi SS, Kim YH, Chae JS, Moon JS, Park H, Kim S, Eo SK. Evaluation of the methicillin-resistant Staphylococcus aureus (MRSA)-screen latex agglutination test for detection of MRSA of animal origin. J Clin Microbiol. 2004;42:2780-2.

39. García-Álvarez L, Holden MT, Lindsay H, Webb CR, Brown DF, Curran MD, Walpole E, Brooks K, Pickard DJ, Teale C, Parkhill J, Bentley SD, Edwards GF, Girvan EK, Kearns AM, Pichon B, Hill RL, Larsen AR, Skov RL, Peacock SJ, Maskell DJ, Holmes MA. Methicillin-resistant Staphylococcus aureus with a novel mecA homologue in human and bovine populations in the UK and Denmark: a descriptive study. Lancet Infect Dis. 2011;11:595-603.

40. Petersen A, Stegger M, Heltberg O, Christensen J, Zeuthen A, Knudsen LK, Urth T, Sorum M, Schouls L, Larsen J, Skov R, Larsen AR. Epidemiology of methicillin-resistant Staphylococcus aureus carrying the novel mecC gene in Denmark corroborates a zoonotic reservoir with transmission to humans. Clin Microbiol Infect. 2013;19:E16-22.

41. Ito T, Hiramatsu K, Tomasz A, de Lencastre H, Perreten V, Holden MT, Coleman DC, Goering R, Giffard PM, Skov RL, Zhang K, Westh H, O'Brien F, Tenover FC, Oliveira DC, Boyle-Vavra S, Laurent F, Kearns AM, Kreiswirth B, Ko KS, Grundmann H, Sollid JE Jr, John JF, Daum R, Soderquist B, Buist $G$, and International Working Group on the Classification of Staphylococcal Cassette Chromosome Elements (IWG-SCC). Guidelines for reporting novel mecA gene homologues. Antimicrob Agents Chemother. 2012;56:4997-9.

42. Holmes M, Zadoks R. Methicillin resistant S. aureus in human and bovine mastitis. Mammary Gland Biol Neoplasia. 2011;16:373-82.

43. Stegger M. Rapid detection, differentiation and typing of methicillinresistant Staphylococcus aureus harbouring either mecA or the new mecA homologue mecA (LGA251). Clin Microbiol Infect. 2012;18:395-400.

44. Stepanovic S, Hauschild T, Dakic I, Al-Doori Z, Svabic-Vlahovic M, Ranin L, Morrison D. Evaluation of phenotypic and molecular methods for detection of oxacillin resistance in members of the Staphylococcus sciuri group. J Clin Microbiol. 2006;44:934-7.
45. de Boer E, Zwartkruis-Nahuis JT, Wit B, Huijsdens XW, de Neeling AJ, Bosch T, van Oosterom RA, Vila A, Heuvelink AE. Prevalence of methicillin-resistant Staphylococcus aureus in meat. Int J Food Microbiol. 2009;134:52-6.

46. Arêde P, Milheiriço C, de Lencastre H, Oliveira DC. The anti-repressor MecR2 promotes the proteolysis of the mecA repressor and enables optimal expression of $\beta$-lactam resistance in MRSA. PLoS Pathog. 2012;8:e1002816.

47. Aldred KJ, Kerns RJ, Osheroff N. Mechanism of quinolone action and resistance. Biochemistry. 2014;53:1565-74.

48. Sierra JM, Marco F, Ruiz J, Jime'nez de Anta MT, Vila J. Correlation between the activity of different fluoroquinolones and the presence of mechanisms of quinolone resistance in epidemiologically related and unrelated strains of methicillin-susceptible and -resistant Staphylococcus aureus. Clin Microbiol Infect. 2002;8:781-90.

49. Xu J, Shi C, Song M, Xu X, Yang P, Paoli G, Shi X. Phenotypic and genotypic antimicrobial resistance traits of foodborne Staphylococcus aureus isolates from Shanghai. J Food Sci. 2014;79:M635-42.

50. Kosmidis C, Schindler BD, Jacinto PL, Patel D, Bains K, Seo SM, Kaatz GW. Expression of multidrug resistance efflux pump genes in clinical and environmental isolates of Staphylococcus aureus. Intl J Antimicrob Agents. 2012:40:204-9

51. Gu"ndog an N, Citak S, Turan E. Slime production, DNAse activity and antibiotic resistance of Staphylococcus aureus isolated from raw milk, pasteurized milk and ice cream samples. Food Control. 2006;17:389-92.

52. Lee HW, Koh YM, Kim J, Lee JC, Lee YC, Seol SY, Cho DT, Kim J. Capacity of multidrug-resistant clinical isolates of Acinetobacter baumannii to form biofilm and adhere to epithelial cell surfaces. Clin Microbiol Infect. 2008;14:49-54

53. Donlan RM, Costerton W. Biofilms: survival mechanisms of clinically relevant microorganisms. Clin Microbiol Rev. 2002;15:167-93.

\section{Submit your next manuscript to BioMed Central and we will help you at every step:}

- We accept pre-submission inquiries

- Our selector tool helps you to find the most relevant journal

- We provide round the clock customer support

- Convenient online submission

- Thorough peer review

- Inclusion in PubMed and all major indexing services

- Maximum visibility for your research

Submit your manuscript at www.biomedcentral.com/submit
() Biomed Central 